\title{
Values, environmental vulnerabilities, and implications on adaptation: Evidence from an indigenous Raika community in Rajasthan, India
}

\author{
Anmol Arora* \\ UNESCO New Delhi Cluster Office, Chanakyapuri, New Delhi, India
}

\section{ARTICLE INFO}

Received: January 14, 2020

Accepted: February 26, 2020

Published: March 11, 2020

*CORRESPONDING AUTHOR

Anmol Arora,

UNESCO New Delhi Cluster

Office, 1, San Martin Marg,

Chanakyapuri - 110 021, New

Delhi, India.

wordsbyanmol@gmail.com

\section{CITATION}

Arora A. (2020). Values, environmental vulnerabilities, and implications on adaptation: Evidence from an indigenous Raika community in Rajasthan, India. International Journal of Population Studies, 6(1):56-68. doi: 10.18063/ijps.v6i1.1066

Copyright: (c) 2020 Arora. This is an Open-Access article distributed under the terms of the Creative Commons Attribution-Non Commercial 4.0 International License (http://creativecommons.org/ licenses/by-nc/4.0/), permitting all noncommercial use, distribution, and reproduction in any medium, provided the original work is properly cited.

\begin{abstract}
Global environmental change has exacerbated the vulnerabilities of pastoral communities in India, who have already been sidelined in the current development and modernization discourse. The Raikas are one of the largest groups of indigenous nomadic pastoralists residing in the semi-arid regions of Northwest India. They are facing the brunt of shrinking grazing areas, social marginalization, and economic pressures. The past two decades have witnessed additional challenges, such as water scarcity and rainfall variability, which have pushed them beyond their adaptive threshold. These churnings have led to a radical shift in their values and climate adaptation strategies. However, the role and importance of social values in shaping their response to environmental change are not well understood. This study conducted life history interviews and focus group discussions with community members to examine social values and their linkages with climate adaptation decision-making in Raikas. The findings demonstrate that the community's livelihood, health, and social cohesion are severely affected by environmental change, entwined with social, economic, and political stressors. There is a parallel change taking place in their social values. Their values related to esteem, self-actualization, safety, and belongingness have witnessed shifts, leading them away from pastoralism. This has ramifications on their adaptation decision-making. Their time-tested and preferred choice of adaptation in the face of drought and water scarcity - seasonal livestock migration - is no longer desirable. New adaptation options, such as urban migration, have emerged, while traditional measures have declined in popularity. There is an urgent need to understand and engage with a broader set of methodologies and literature to facilitate the integration of social values in vulnerability and adaptation assessments. The inclusion of social values presents an opportunity to understand the subjective limits of adaptation better as well as to expand adaptation pathways.
\end{abstract}

Keywords: Climate change, Environmental vulnerability, Indigenous community, India This article belongs to the Special Issue: Environment and Population Dynamics in South Asia

\section{Introduction}

Adaptation can be defined as the "adjustment in natural or human systems in response to actual or expected climatic stimuli or their effects, which moderates harm or exploits beneficial opportunities" (IPCC TAR, 2001: 982). The need for adaptation has outpaced its implementation, leading to an adaptation deficit (Eisenack, Moser, Hoffmann, et al., 2014). Therefore, it has become imperative to identify the limits of adaptation and overcome them. Most discussions on the limits of adaptation focus on external factors such as technology, ecology, and economy. This approach to envisioning the limits to adaptation is appealing because it provides analytical functionality, which aligns well with the other important dimensions of climate change analysis, namely, modeling variations in the earth system and energy-economic modeling of mitigation policy (Adger, Dessai, Goulden, et al., 2009: 337). While useful, these methods exclude the 
cultural embeddedness of risks and overlook the everyday experiences, interpretations, and negotiations with environmental change (O’Brien, 2009; Jones and Boyd, 2011; Adger, Barnett, Brown, et al., 2013; Dow, Berkhout, and Preston, 2013).

Values, in their most open and broadest form, refer to what is considered desirable within an individual or society (Adger, Dessai, Goulden, et al., 2009; O'Brien and Wolf, 2010). They are ubiquitous and serve as guidelines or standards for our action, judgment, attitudes, desires, evaluations, and arguments. Therefore, it is essential to understand the values that shape human behavior to environmental change (Rokeach, 2008). The values-based approach to adaptation addresses climate change from the lens of how a society is organized and how the relationship between individuals, institutions, and the state is structured (Ramm, Graham, White, et al., 2017). It makes explicit the non-material parts of what people deem important and cherish about their lives, how environmental change impacts them, and how policies are framed (O'Brien and Wolf, 2010; Graham, Barnett, Fincher, et al., 2013).

The Raika community is one of the largest groups of indigenous nomadic pastoralists located in Rajasthan (Geerlings, 2011) and has been connected to livestock through myths of origin (Sharma, Köhler-Rollefson, and Morton, 2003). However, the shrinking of grazing areas, indifferent policy, financial pressures, and environmental change have led them to a crisis of livelihood and identity (Sansthan, 2004; Sharma and Sharma, 2015). Raikas operate in an environment characterized by low and erratic rainfall, low humidity, and high wind velocity. Rajasthan experienced 48 droughts of varying intensities between 1901 and 2002, which means that the chance of occurrence of a drought in the state is 47\% (Rathore, 2004). Analysis by Singh and Kumar (2015) reveals a $50 \mathrm{~mm}$ decrease in the average annual rainfall between 1973 and 2008. The past two decades have witnessed acute water scarcity and rainfall variability (The Energy and Resources Institute, 2010; Pareek and Trivedi, 2011; Down to Earth, 2018; Sharma, Sharma, Panda, et al., 2018). Seasonal livestock migration has been their adaptation of choice for decades, but it is not adequate or even desired anymore. There have been many studies on Raikas, but only a handful of them focus on their biophysical vulnerabilities. This research seeks to examine the extent, to which their adaptation practices are contingent on sociocultural values, access to resources, information, and power. Its objectives include the analysis of where, when, and how limits on adaptation arise and the social justice concerns that come into play. This study will help evaluate the utility of a values-based approach to adaptation and help strengthen state programs and policies.

\subsection{Conceptual Framework}

This study uses Graham, Barnett, Fincher, et al.'s (2013) framework to define and operationalize values. Their study reviews five disciplines - social impact assessment, climate adaptation, decision analysis, psychology, and human geography - to define values. Lived values can be defined as the "valuations that individuals make, in isolation or as part of a group, about what is important in their lives and the places they live" (Graham, Barnett, Fincher, et al., 2013: 15). As illustrated in Figure 1, this definition of lived values is followed by a categorization using Maslow's hierarchy of needs. The primary groupings are: Self-actualization, safety, health, belongingness, and esteem.

\section{Data and Method}

\subsection{Study Design}

A qualitative research design, using the case study approach, was employed to understand the linkages between the values and adaptation decisions of the Raika community in Rajasthan. The case study approach is particularly useful and can be widely applied to "gather a coherent and complete theory of migration related to environmental change" (Piguet, 2010: 522). The qualitative approach is suitable because it makes explicit that there are subjective, qualitative dimensions to environmental change that is of importance to individuals and cultures (O'Brien, 2009).

\subsection{Study Site}

The Rajasthan state, located in Northwest India, has an area of 342,000 sq. km. and more than half of this area falls under the arid category (Roy, 2014). The three districts selected for data collection were Sirohi, Jalore, and Pali, which are located in Southwest Rajasthan and have sizeable Raika populations. The literature review had affirmed the Raikas presence in these districts as well as its importance as a migratory route for this community.

\subsection{Ethical Statement}

The research design, tools, and process were reviewed and approved by the International Development Ethics Committee at the University of East Anglia. The purpose of the research was explained to all participants and oral consent obtained from them. The data were anonymized at the transcription stage to prevent any breach of confidentiality. 


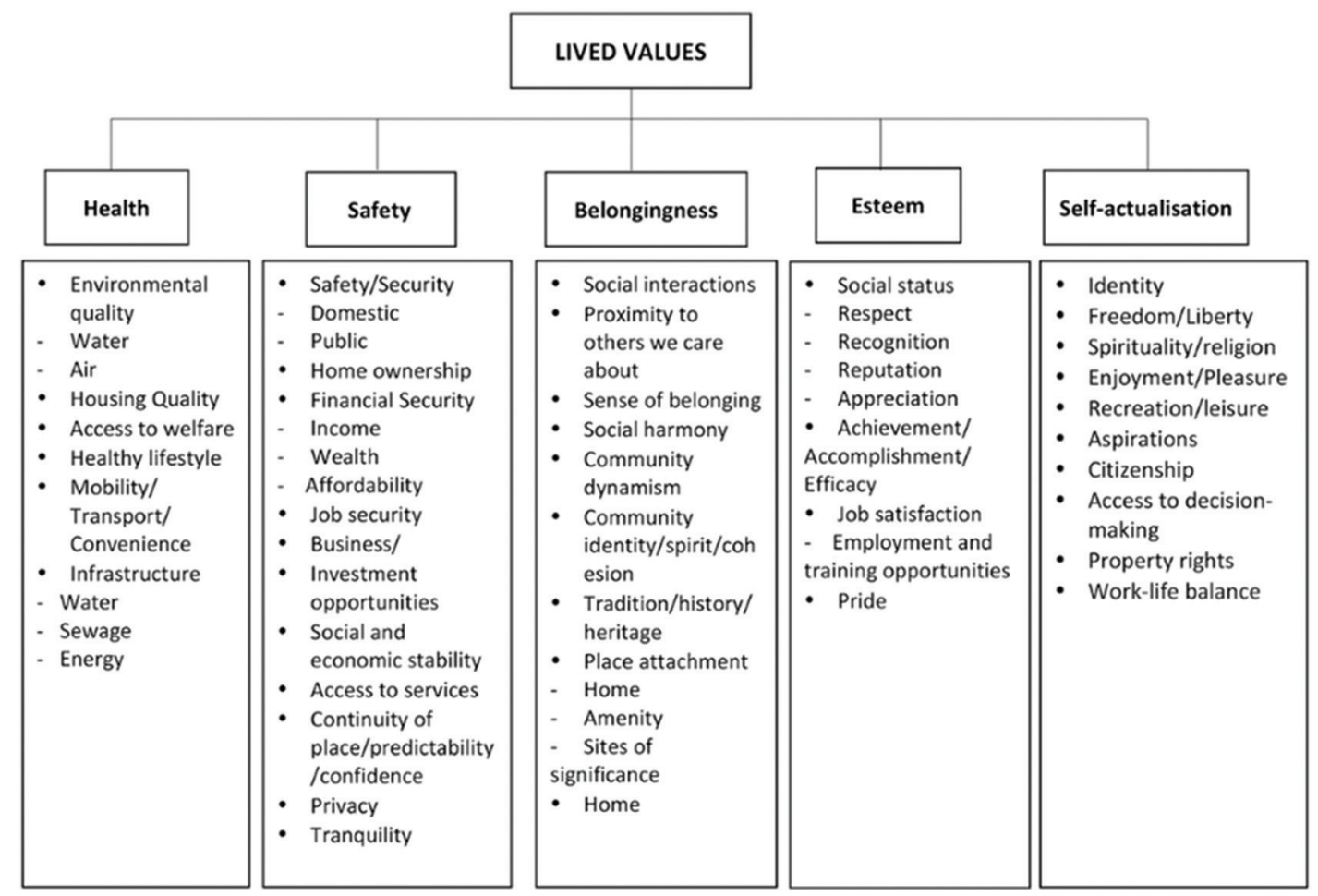

Figure 1. The categorization of lived values that may be affected by sea level rise.

Source: Graham, Barnett, Fincher, et al. (2013).

\subsection{Data Collection}

The study employs two different data collection tools, namely, life history interviews and focus group discussions. Nineteen life history interviews and two focus group discussions were conducted in the course of a month in Rajasthan. The mode of life history interviews allows respondents to talk freely and flexibly (Anderson and Jack, 2002). Interviews are a useful instrument to explore social values and are well-suited to research where the respondent's in-depth opinions are being sought (Bryman, 2016). Focus group discussions were initially not part of the research design. These were conducted during community celebrations held in Pali and Sirohi districts, to which the author was invited. The facilitation of Lokhit Pashu-Palak Sansthan (LPPS) a local Non-Governmental Organization, as well as the community's presence, made these possible. There were 15 male participants in each of these two discussions. Leveraging this opportunity, the researcher prepared a set of questions based on environmental risks, social values, and risk management strategies, and allowed the respondents to share their personal experiences, beliefs, and perceptions through a moderated discussion. This technique allowed for different perspectives to emerge, be contested, and be cross-checked.

\subsection{Sampling}

The snowball sampling method was employed for this study. The dearth of official records on the Raikas and accessibility challenges due to their migration cycle made snowballing necessary. First, contact was established with a local Raika, who agreed to facilitate introductions in Pali and Sirohi districts and translate from the local dialect to Hindi. A second data collection activity was conducted in Jalore district through LPPS, which works closely with the Raika community. This process led to the selection of 18 respondents and one key informant. The key informant was selected due to her deep knowledge and close association with the Raikas. The main characteristics of the respondents are presented in Table 1.

\subsection{Data Analysis}

The study identified and selected respondents' descriptions of values that matched the themes in Graham, Barnett, Fincher et al.'s lived values framework (2013). The five values are (i) esteem, (ii) self-actualization, (iii) safety, (iv) health, and (v) belongingness. Two separate sets of codes were created: One for past values and the other for new values. Through 
Table 1. Characteristics of selected participants.

\begin{tabular}{|c|c|c|c|c|c|c|}
\hline Identifier & Gender & District and village & Occupation & Age & Herd type & Herd size \\
\hline $\mathrm{P} 2$ & Male & Pali & Pastoralist & 35 & Sheep & 30 \\
\hline P3 & Male & Pali & Pastoralist & 32 & Sheep and goats & 80 \\
\hline P4 & Male & Sirohi & Pastoralist & 35 & Sheep and goats & 60 \\
\hline P5 & Male & Pali & Pastoralist & 45 & Sheep & 100 \\
\hline P6 & Male & Pali & Pastoralist & 55 & Camels & 40 \\
\hline P7 & Female & Pali & $\begin{array}{l}\text { Entrepreneur and social } \\
\text { worker (key informant) }\end{array}$ & N.D. & N.A. & N.A. \\
\hline P9 & Male & Pali & Pastoralist & 60 & Goats, sheep, and cow & 40,20, and 1 \\
\hline P10 & Male & Pali & Pastoralist & $60-70$ & Goats and sheep & 30 \\
\hline P11 & Male & Pali & Pastoralist & 35 & Goats, camels, and sheep & 35,15 , and 150 \\
\hline P12 & Male & Pali & Pastoralist & $60-70$ & Sheep and goats & 40 \\
\hline P13 & Female & Pali & Pastoralist, laborer, and agriculture & N.D. & Goats and sheep & 25 and 30 \\
\hline P14 & Male & Pali & Entrepreneur & 55 & None & None \\
\hline $\mathrm{P} 15$ & Female & Pali & Pastoralist & 65 & Goats and sheep & 45 and 35 \\
\hline P16 & Male & Jalore & Laborer & 20 & None & None \\
\hline P17 & Male & Jalore & Pastoralist & 60 & Sheep & 40 \\
\hline P18 & Male & Pali & Pastoralist & 35 & Goats & 200 \\
\hline P19 & Female & Pali & Homemaker and laborer & 40 and 42 & N.A. & N.A. \\
\hline $\mathrm{P} 20$ & Male & Jalore & Pastoralist & 60 & Sheep & 40 \\
\hline P21 & Male & Pali & Pastoralist and entrepreneur & 42 & Cows and buffaloes & 15 \\
\hline
\end{tabular}

this process, a clear comparison between past and current values was made. The analysis used NVivo 12 software. Subsequently, the study identified the biophysical, political, and socioeconomic vulnerabilities of the Raikas and the resultant adaptation decisions. This exercise allowed the study to juxtapose the social values and vulnerabilities against the adaptation decisions. This process enables the discovery of similarities, differences, and linkages between and within these three elements (Seidel and Kelle, 1995: 55-56).

\section{Results}

\subsection{Value shifts in Raikas}

This study observed a definite shift in the lived values of Raikas across four of the five domains of Graham, Barnett, Fincher et al.'s framework (2013). Raikas experience a sense of inferiority and disillusionment about their current socioeconomic status. They feel left behind in the development and modernization discourse and are making efforts to move away from their traditional values, lifestyle, and livelihood practices. Traditionalism, in their context, refers to a firm adherence to Hinduism, patriarchy, and traditional practices and livelihoods; less emphasis on formal, western education; community living; and having large families (Inglehart and Baker, 2000). Westernization and modernization would imply the opposite traits and give precedence to western attire, education for women, freedom to choose a partner, etc. (Inglehart and Baker, 2000). The previous studies have found that the Raikas in the neighboring state of Gujarat also perceive themselves as a "backward group" that is excluded from the development around them (Dyer, 2012).

\subsubsection{Esteem}

In the past, Raikas associated esteem-related values (Table 2) such as social status, pride, and job satisfaction directly with their livestock quantity and nomadic pastoralism (LPPS, 2004). The larger a person's livestock, the more prestige and respect they enjoyed within the community.

"For us, the real wealth was our number of cattle. If you had 200 goats, people would be happy to give you their daughter in marriage." (55-year-old Raika) 
Table 2. The change in the accomplishment value of a pastoralist.

\begin{tabular}{lll}
\hline Lived values & Past value quotes & Present value quotes \\
\hline Esteem & "There was a lot of prestige associated with & "I left migration. If I migrate with livestock, my \\
& migration and plenty of livestock." & $\begin{array}{l}\text { children's education will suffer. I was wild, and my } \\
\text { children will also become wild like me." }\end{array}$ \\
\hline
\end{tabular}

The practice of seasonal livestock migration also enhanced their social status, respect, and pride. They cherished the freedom, enterprise, and sense of adventure that is inherent in this practice.

"I used to enjoy going to Madhya Pradesh with my livestock. Everyone used to treat us well. They would give us food to eat. We would smoke bidi." (35-year-old Raika)

Chemical fertilizers have replaced cattle manure, which was provided by the Raikas in return for the farmers' hospitality. This respondent has stopped the practice of seasonal livestock migration. The same sense of esteem is now derived from education, government or private jobs, entrepreneurship, ability to speak English, and western clothes such as trousers and shirts.

\subsubsection{Belongingness}

Belongingness entails values such as social interactions, place attachment, and traditions. The Raikas' sense of belongingness was closely attached to many of the unique elements of their culture, such as the dang groups in which they migrated, their traditional attire, and their livestock. The Raikas are the only community to use camels on the occasion of nikasi, the departure of a groom's marriage party, and at the toran, the entrance of the bride's house (Tripathi and Rajput, 2005). These practices have dwindled in the past two decades. For example, the seasonal livestock migration in dangs has decreased.

"This is our inter-generational work. My father kept livestock, and his father, before him. I used to accompany my father every day and learned how to tend to livestock. It is what we studied, but the new generation doesn't do that." (55-year-old Raika)

\subsubsection{Safety}

The notion of safety was inextricably linked to their livestock until two decades ago. It provided Raikas a regular stream of income through the sale of animals, wool, dairy, and dung. Moreover, the milk and clarified butter derived from the livestock are essential ingredients of their daily diet. One Raika claimed that he would go hungry but not let the same happen to his camel. His resolve toward the well-being of his livestock demonstrates the importance of livestock in his life.

Things are changing fast in the safety domain as well. The past two decades have seen a breakdown of cooperation with farmers, scuffles, and thefts during migration cycles, low prices of wool, and overall financial hardship. Ninety percent of respondents stated that they are experiencing financial hardship and face personal safety risks in livestock migration. Thus, the sense of predictability, confidence, and safety that was derived from livestock ownership and seasonal livestock migration is no longer present.

\subsubsection{Self-actualization}

Earlier, the self-actualization values of the Raikas, such as identity, religion, freedom, ability to better themselves, worklife balance, and social mobility, were contingent on their livestock and social cohesion. The older generation advised the younger generation to focus on taking care of the cattle. The popular myths spoke of their sacred duty to protect and preserve camels. There was a sense of joy derived from a lifestyle closely attached to livestock.

"My father and I used to go together for cattle grazing to the forest. I would follow him. This way, I learned how to drive cattle, how to herd them, where they can be fed water. We did that together. I used to enjoy it." (60-year-old Raika)

This shows that livestock was inextricably attached to their sense of identity and freedom. The same respondent is now eager to sell his livestock.

"I saw and heard from people that it is important to get the kids to study. So, we enrolled them in a primary school. The kids are now saying that father, you are right. If you had studied, we would have been even better." (60-year-old pastoralist)

Thus, livestock management, which earlier offered them self-actualization traits like freedom and identity, is now perceived to be disadvantageous. 


\subsubsection{Health}

In this study, "Health" is an outlier value since its parameters have not changed in the past two decades. The health value is concerned with the natural and social ecosystems in which Raikas operate, such as water, air, lifestyle, access to welfare, and infrastructure. Many respondents alluded to the fact that a rural lifestyle leads to better health outcomes. They pointed to the availability of better quality of air, food, housing, and overall lifestyle in villages. This indicates that the health value has remained aligned with their traditional lifestyle. Despite the admitted benefits, Raikas want their children to move to urban areas.

"The air in rural areas is fresh. The city has stale air. I was in Mumbai for 18 years, and I had to switch the fan on during the day. When I go to the jungle, I don't need a fan." (35-year-old pastoralist, who was keen to send his kids to the city despite health challenges there)

Thus, it can be surmised that the Raikas are willing to deprioritize the health value.

\subsection{Multidimensional Vulnerabilities}

This study contends that Raikas face multidimensional vulnerabilities that have their roots in the distribution and access to resources, information, and power. They reside in the outskirts of rural areas, away from the benefits of mainstream resources. Furthermore, their low-caste and ethnic status renders them unable to meaningfully participate in the governance processes. As a result, they are unable to put their interests and concerns in the public domain. Their financial capital has diminished with the marginalization of pastoralism and the breakdown of cooperative relationships with farmers. Environmental change is an additional strain on the already stressed sector. Rainfall variability and water scarcity cause a multiplier effect that pushes them beyond their adaptive capacity.

\subsubsection{Government schemes, programs, and policies}

Over the past two decades, the Raika community has faced a severe shortage of grazing land for their livestock (Geerlings, 2004). All the respondents that maintain livestock highlight this as the main threat to their livelihood. Conventionally, villages had common grazing land known as gauchar, and patches of jungle known as oran, reserved in the name of deities. These were open for cattle grazing. The Rajasthan Tenancy Act and the Allotment of Land for Agricultural Purposes Rules protected village lands from being turned into private agricultural land (Land Revenue Portal, n.d.). However, these commons have become increasingly diverted for other purposes (Geerlings, 2004; Sansthan, 2004). In the 1970s, the national government introduced a new forestry bill that allowed the local village council, called panchayat, to fence off common lands to improve vegetation cover. The resultant inability to find pasture directly affects the health of the livestock and has financial implications for the Raikas. During this study's fieldwork in June 2019, local newspapers reported a new bill by the State Government that would cordon off forest areas into the protected territory. It would make Kumbhalgarh Forest Area, a 562-sq. km. reserved forest, inaccessible for cattle grazing.

"If they stop us from the jungles and make it a national park, that's the end of us. We will have to beg for our food." (35-year-old pastoralist)

On June 30, 2014, the Government of Rajasthan designated camel as the state animal. The Rajasthan Bovine Animal (Prohibition of Slaughter and Regulation of Temporary Migration or Exports of the Camels) Bill 2014 was introduced to preserve the dwindling camel population, and to prevent the smuggling and migration of camels (Deccan Herald, 2014; Press Trust of India, 2014). With the Governor's assent, the act introduced severe punishment for selling camels for slaughter, for taking them outside the state, for castrating them, and even for using the nose peg (Köhler-Rollefson, 2015). The unintended consequence and faulty implementation of this legislation meant that it put a question mark on the citizen's right to rear and migrate camels - a routine activity of the Raikas. It impinged directly on their primary source of livelihood.

\subsubsection{Biophysical factors}

In the context of biophysical factors, the majority of the respondents pointed to the problem of low rainfall and water scarcity. Their perception was that the rainfall has decreased in the past two decades. They also point out that river Luni has dried up. The ramification of this situation is that the Raikas have had to search for other water sources for their livestock. This entails a variety of decisions, ranging from longer and farther migration to livestock reduction. Their observation is corroborated by Singh and Kumar's study (2015), which shows a $50 \mathrm{~mm}$ decrease in rainfall over the past 30 years in Western Rajasthan. The Raikas posit that low rainfall leads to low grass cover, which links directly to the unavailability of cattle fodder. This shortage of fodder would then decrease the productivity of livestock and impact them 
financially. Thus, we can see that the vulnerability of the Raikas to environmental change is high as they rely heavily on natural resources for livestock management, whose availability is increasingly uncertain.

"If there is less rain, there will be less agricultural production. If there is less agriculture, there will be less fodder for my livestock. It is all interdependent." (60-year-old pastoralist)

The variability in rainfall directly impacts livestock management and agriculture. Heavy rainfall brings a different set of challenges. Sheep and goats refuse to walk in waterlogged areas, and thus, feeding them becomes a challenge. It also exposes livestock to physical injury as their hooves get puffed, insects take shelter in the grooves, and they are more prone to stepping on poisonous angrezi babul (Prosopis juliflora) thorns in these conditions. Finally, the risk of loss of agricultural produce due to heavy rains can lead to a shortage of fodder for cattle.

"The rainfall has decreased significantly. Where is the rainfall now? Now, it comes for a few days and then goes. Earlier, it used to rain for all four months." (55-year-old Raika)

\subsubsection{Socioeconomic factors}

The Raikas are also investing more financial resources in educating their children. This is an additional expenditure that needs to be borne from their meager pool of resources. It was not part of their financial expense earlier, as the children were expected to undertake livestock management.

"My son is good in studies. So, I have put him in a private school. If we pay money, they will make him study... There is a village nearby that is good for education, but the expense is high." (55-year-old Raika)

Furthermore, the shrinkage of pastures and inaccessibility of forests is forcing them to purchase fodder from farmers or pay grazing fees to the forest department (Sharma and Sharma, 2015). There has also been a decrease in the selling price of wool and dairy attributed to government import of second-hand wool from abroad. All of these factors are leading to a decrease in their financial capital.

There are considerable safety risks faced by the Raikas in their day-to-day lives. These range from the breakdown in their relationship with farmers to the threat of theft and physical violence during seasonal livestock migration. The literature indicates a harmonious and symbiotic relationship with farmers in the past (Agrawal, 1993; Geerlings, 2004). Raikas' cattle supplied manure to farmers, and the same fields could be used for fodder. The shift toward chemical fertilizers and round-theyear cultivation has led to a reduction of fallow periods, turning the Raikas into unwelcome guests. This has caused further marginalization and isolation of the community. A 45-year-old pastoralist reported this about the treatment meted out to them by farmers: The farmers tell them, "Hey, this is my property. Take them [the cattle] out of here." Their lived experience of conflict and theft during the migration cycle is corroborated by multiple studies (Agrawal, 1994; Geerlings, 2004; LPPS, 2004).

\subsection{Adaptation Pathways}

\subsubsection{Seasonal livestock migration, reduction, and sale}

Seasonal livestock migration is the Raikas' traditional adaptation pathway to environmental vulnerabilities. It entails migrating at the end of the monsoon season and continues for 6-9 months, contingent on fodder and water availability (Agrawal, 1993). When asked how they would respond to a drought tomorrow morning, all the livestock-rearing respondents spoke about the necessity of migration.

"As long as we keep livestock, we will have to migrate during drought." (35-year-old Raika)

Seasonal livestock migration remains a viable adaptation option in the face of severe environmental distress. However, as shown earlier, this strategy is declining in popularity in the past two decades and is practiced as a measure of the last resort. It meets their health values as it allows them to enjoy the pristine rural environment and lifestyle. However, it does not offer them safety, belongingness, accomplishment, or self-actualization.

Livestock reduction, on the other hand, entails periodic selling of cattle to meet household expenses. The past two decades have witnessed more and more households employing this strategy. A lesser number of livestock allows them to become sedentary as they can find sufficient fodder for them in the nearby areas. It also insulates them from heavy financial losses that may arise if their livestock's health deteriorates in harsh environmental conditions. Some Raikas choose to sell off their entire cattle and shift to other livelihood strategies. These alternative sources of livelihood better shield them from environmental stressors and offer them the opportunity to become sedentary, which has gained prestige and prominence. Thus, this strategy is more aligned with safety, belongingness, health, and self-actualization values.

"I sell livestock for money. It is important for us. The whole family is dependent on it. We are also selling because if we keep less, we can manage with less fodder." (35-year-old Raika) 


\subsubsection{Urban migration and informal sector employment}

Urban migration is a relatively new adaptation option for the Raika community. It entails moving to cities such as Ahmedabad and Mumbai to work in the informal sector. More and more young men are exercising this option at the expense of livestock management, which is heavily impacted by environmental vagaries. They receive support from an increasing number of Raikas who have moved to these urban centers in the recent past. This option is congruent with all their values except health. These informal work and entrepreneurial opportunities are readily available in the city and provide financial safety. The Raikas now relate to the belongingness and esteem that comes with the western attire and lifestyle prevalent in the cities.

"There is no place like Ahmedabad in all of India. No matter who goes there, he will return with 500 rupees in the evening." (55-year-old Raika)

Many Raikas gain employment in garment and grocery stores or as watchmen in newly constructed buildings in and around rural areas. It is an adaptation strategy practiced by Raikas who shift their livelihood away from livestock management but continue to reside in rural areas.

"The youth sets up business like a shop. Then we do not want to do livestock management. The income from livestock is not much. You have to follow them [the livestock] all day. For the previous generation, this was their work. The current generation does not want this." (20-year-old Raika)

These jobs offer them greater financial safety through a guaranteed monthly income. It is also more in tune with the self-actualization, belongingness, health, and esteem values.

Selling milk is another livelihood-diversification strategy adopted by Raikas. It involves the sale of camel milk to consumers across Rajasthan through the storage and supply chain support provided by LPPS. It offers them a regular stream of income that can be utilized to meet household requirements in times of environmental stress. Two of the respondents of this study who practice camel-rearing are taking part in this livelihood activity. The study finds it to be congruent with their safety, self-actualization, and health values. First, this activity provides financial safety by assuring a constant stream of income. Second, it provides health benefits as Raikas can stay in their village. Third, it provides the freedom to move and work as they please, leading to self-actualization.

"It is better to live here in our village. I can feed cattle here and go home when work is complete. I can live with my people, meet my people, and do my duty." (55-year-old pastoralist)

\subsubsection{Education}

This adaptation pathway entails investment in children's primary education as a means to ultimately transition away from livestock management. All the respondents believe that the skills accrued by education can generate better livelihood opportunities and reduce dependence on natural resources.

"There is no space for fodder anymore. My grandchildren will go to school." (80-year-old Raika)

Education was deemed important, especially in the absence of livestock and increasing water scarcity. They expect better livelihood outcomes and higher social standing as a result of investing in their children's education. Many respondents mentioned education as the causal factor behind the improvement in the financial condition of some families, visible as concrete houses and western clothes. Thus, the study finds greater financial safety, esteem, belongingness, and self-actualization associated with education.

\section{Discussion}

This study finds linkages between social values and adaptation choices made by the Raika community in Rajasthan. Their social values, such as accomplishment, esteem, safety, and belongingness, have changed drastically in the past two decades. Previously, these values were aligned with traditional lifestyle and livelihood practices, but this is no longer the case. The Raikas have begun to favor modern and western values over traditional ones. Environmental change is a catalyst for these shifts. It acts as an amplifier of their structural vulnerabilities and diminishes their adaptive capacity. Social and spatial marginalization renders them unable to participate in the local governance process. As a result, policy measures have failed to accommodate their concerns and have had a detrimental effect on their livelihoods. Their adaptation strategies have witnessed a concomitant shift. These linkages between values and adaptation choices imply the need to include lived values as an integral element in the conceptualization and design of climate adaptation programs, policies, and processes. For the needs of research, the integration of social values into environmental vulnerabilities assessments will require engaging with a diverse set of literature on the linkages between climate change, on the one hand, and religion, culture, ethics, and psychology, on the other hand. 
Seasonal livestock migration, which was the trusted adaptation strategy of the Raikas in the face of drought and water scarcity, has been sidelined by urban migration, education, and private jobs. In the past, entire villages would migrate with their livestock during the dry season. This adaptation strategy spoke of social cohesion and allowed them to achieve the belongingness value. A higher quantity of livestock was a source of esteem. It offered them financial safety and even determined marriage alliances. The same belongingness is now derived from wearing trousers and shirts like city dwellers. Marriage alliances are based on the level of education and ability to secure private jobs. This finding gives credence to the argument that social and individual characteristics limit adaptation (Adger, Dessai, Goulden, et al., 2009; O'Brien, 2009; O'Brien and Wolf, 2010; Grothmann and Patt, 2005; Neef, Benge, Boruff et al., 2018). It implies that adaptation policy and practice must appropriate an understanding of the importance of social values to build sustainable adaptation pathways. Taking this argument further, this study highlights that the decline of seasonal livestock migration is matched by the rise in urban migration and education. The practice of these adaptation pathways is relatively new and driven by a change in social values. It must also be noted that power and preference foreground the expansion of adaptation pathways (Pelling, O’Brien, Matyas, et al., 2015; Fook, 2017). This study advances this argument to posit that value preferences can not only limit adaptation but also offer a means to expand adaptation pathways.

This study also observes the dynamic and conflicting nature of values. Economic, demographic, and biophysical changes exert influence on Raikas' value systems and produce tensions. The youth have migrated to cities and are driven by ambitions of material wealth and consumption. They are often unwilling to partake in local customs and livelihood practices, while the older generation seeks to preserve some of these practices. This shift is consistent with the findings from other pastoralist communities such as Bhotiyas of Kumaon region in Central Himalayas in India, where young adults are discarding traditional practice in search of jobs in urban centers (Cultural Survival, 1998). The fact that there exist generational differences in values has been corroborated by Inglehart and Baker (2000) and O'Brien (2009). The insights on dynamism and conflicting nature of values build the evidence base for adaptation relative to place, time, and subjectivities.

The study raises questions on the social justice implications of adaptation, especially when it entails trade-offs in the allocation of resources. Masking these trade-offs marginalizes the less powerful groups and raises questions of social justice (Graham, Barnett, Fincher, et al., 2015). This dynamic is currently playing out in the rural areas of Rajasthan. The village commons have been fenced and closed for cattle grazing by powerful groups in the name of environmental protection. The inability to use these grazing areas has made it difficult for the Raikas to eke out a livelihood from livestock management. These conditions mean that adaptation policy needs to consider the interests and objectives of multiple stakeholders and identify the trade-offs that come with adaptation choices. Doing that would shed light on the winners and losers of adaptation as well as its acceptable and unacceptable losses (Nalau, Handmer, Dalesa, et al., 2016; Neef, Benge, Boruff, et al., 2018).

There has been little accommodation for sociological, legal, and philosophical perspectives on intergenerational rights and responsibilities (Rayner and Malone, 2001; Gibbons, 2014). Some of these tensions became visible in this study. For example, the Raikas invest time and financial resources on their children's education and encourage them to migrate to urban areas for work. These adaptation choices entail the compromise of their current adaptive capacity for future gains. Further, these choices trap older adults in villages, without adequate financial means and family support, to pursue livestock management. A similar development was recorded in Odisha, where the youth migrated to urban areas (after natural disasters), leaving the older adults to fend for themselves (Patel, Mathew, Nanda, et al., 2020). Therefore, adaptation can involve intergenerational tensions as well as the sacrifice of short-term adaptive capacity to bolster long-term adaptive capacity. This study makes a case for closer scrutiny of these intergenerational dynamics.

It is not advisable to consider environmental vulnerabilities in isolation (Assessment A.C.I., 2004; O'Brien, 2008; McCubbin, Smit, and Pearce, 2015). Adaptation policies that do not respond to a suite of forces (socioeconomic, cultural, and political) run the risk of increasing vulnerabilities. This study reinforces the point that adaptation needs to be designed in response to multiple interacting forces. For instance, the study found that even when seasonal livestock migration was a viable option against environmental stressors, the sociopolitical context made the strategy unviable. The breakdown of the relationship between farmers and the Raikas meant that the farmers are unwilling to offer them shelter and food during their migration cycle. Furthermore, there is an increased occurrence of cattle theft by raiders, putting the Raikas in harm's way. This shows that their vulnerability is a result of a combination of factors. This study builds the argument that addressing these structural issues will allow adaptation policy to have a long-term impact. 
Finally, the paper contributes to the literature on inclusive and participatory adaptation. It is imperative that there is meaningful participation of all stakeholders in governance mechanisms (Few, Brown, and Tompkins, 2007; Ayers, 2011). The study highlights that the Raikas find no space for participation in the local governance process. As a result, policy measures often have had a disastrous impact on their livelihood and adaptive capacities. For example, the closure of the Kumbhalgarh Forest Area to cattle grazing has been a death knell for the Raikas. A law designed to protect the dwindling camel population has had the unintended consequence of making it difficult for the Raikas to tend to their camel livestock. This study shows that adaptation needs to take an inclusive approach that puts local interests, knowledge, and aspirations at the front and center of the decision-making process.

The main limitation of this study is the lack of participation of young adult males as well as women. The study is skewed toward older male household heads as most of the young males had migrated out in search of jobs. Similarly, women are not adequately represented in this study because of cultural norms that made their participation difficult.

\section{Conclusion}

This study highlights that the Raikas are disproportionately affected by environmental stressors. Rainfall variability, water scarcity, and drought, in combination with structural vulnerabilities, are pushing them beyond their adaptive threshold. This paper has added to the understanding of the shift in their values and multidimensional vulnerabilities and how they relate to the Raikas' adaptation decision-making. It suggests that there has been a marked shift in esteem, safety, self-actualization, and belongingness values, which has driven the changes in their adaptation choices. New adaptation options, such as urban migration, have emerged, while traditional measures have declined in popularity.

This study recommends policymakers and researchers to engage with a wider set of methodologies and literature to facilitate the integration of social values in vulnerability and adaptation assessments. The integration of social values presents an opportunity to understand the subjective limits of adaptation better as well as to expand adaptation pathways. It is important to consider the intergenerational elements in adaptation decision-making and to undertake holistic studies to arrive at the multidimensional vulnerabilities and their linkages with adaptation decision-making. This will contribute toward adaptation policies that are people-centric, sustainable, and grounded in the local realities.

\section{Author's Contribution}

Anmol Arora conceived, designed, and implemented the study, including data analysis and presentation, interpretation, and discussion of the results.

\section{Conflicts of Interest}

The author declares that they have no conflicts of interest.

\section{Consent}

Informed verbal consent was obtained from each of the respondents who participated in the study.

\section{Ethical Approval}

The ethical approval for this research was granted by The International Development Ethics Committee at the University of East Anglia, the institution that oversaw the conduct of this research.

\section{Acknowledgment}

The author would like to express his gratitude to Dr. Heike Schroeder for her guidance and support. This study is better because of the mentorship of Dr. Aditya V. Bahadur and Dr. Rita Arora.

\section{Funding}

This research was funded by the University of East Anglia DEV support fund.

\section{Availability of Supporting Data}

All data files used in this manuscript are available on the Harvard Dataverse at the link given here: https://doi.org/10.7910/ DVN/KZS4BB. 


\section{References}

Adger WN, Barnett J, Brown K, Marshall N, et al. (2013). Cultural dimensions of climate change impacts and adaptation. Nature Climate Change, 3(2): 112. https://doi.org/10.1038/nclimate1666.

Adger WN, Dessai S, Goulden M, et al. (2009). Social limits to adaptation. Climatic Change, 93(3-4): 335-354. https://doi.org/10.1007/ s10584-008-9520-z.

Agrawal A. (1993). Mobility and cooperation among nomadic shepherds: The case of the Raikas. Human Ecology, 21(3). https://doi. org/10.1007/BF00891539.

Agrawal A. (1994). These kinds of "I don't want it, but you can’t have it" politics on the commons. Pastoral Development Network. 36a: $36-55$.

Anderson K and Jack DC. (2002). Learning to listen: Interview techniques and analyses. In R Perks and A Thomson (Eds.), The Oral History Reader (pp. 157-171). London: Routledge.

Assessment A.C.I. (2004). Impacts of a Warming Arctic-Arctic Climate Impact Assessment. Cambridge, UK: Cambridge University Press.

Ayers J. (2011). Resolving the adaptation paradox: Exploring the potential for deliberative adaptation policymaking in Bangladesh. Global Environmental Politics, 11(1): 62-88.

Bryman A. (2016). Social Research Methods. New York: Oxford University Press.

Cultural Survival. (1998). Changes in pastoralism in the Indian Himalaya. Available from: https://www.culturalsurvival.org/publications/ cultural-survival-quarterly/changes- pastoralism-Indian-Himalaya. [Last accessed on 2019 July 25].

Deccan Herald. (2014). Rajasthan Government's move to save camel backfires. Available from: https://www.deccanherald.com/ content/419372/rajasthan-govts-move-savecamel.html. [Last accessed on 2019 June 08].

Dow K, Berkhout F, and Preston BL. (2013). Limits to adaptation to climate change: A risk approach. Current Opinion in Environmental Sustainability, 5(3-4): 384-391.

Down to Earth. (2018). Climate change in India: Either adapt or perish in Rajasthan. Available from: https://www.downtoearth.org.in/ news/climate-change/climate-change-in-indiaeither-adapt-or-perish-in-rajasthan-61875. [Last accessed on 2019 April 28].

Dyer C. (2012). Formal education and pastoralism in western India: Inclusion, or adverse incorporation? Compare - A Journal of Comparative and International Education, 42(2): 259-81.

Eisenack K, Moser SC, Hoffmann E, Klein RJ, Oberlack C, Pechan A, Rotter M, Termeer CJ. (2014). Explaining and overcoming barriers to climate change adaptation. Nature Climate Change, 4(10): 867-72.

Few R, Brown K, Tompkins EL. (2007). Public participation and climate change adaptation: Avoiding the illusion of inclusion. Climate Policy, 7(1): 46-59. https://doi.org/10.1080/14693062.2007.9685637.

Fook T. (2017). Transformational processes for community-focused adaptation and social change: A synthesis. Climate and Development, 9(1): 5-21.

Geerlings E. (2004). The black sheep of Rajasthan. Available from: https://www.grain.org/article/entries/436-the-black-sheep-ofrajasthan. [Last accessed on 2019 April 22].

Geerlings E. (2011). Nomadic livelihoods at stake in Rajasthan, India. Available from: https://ellengeerlings.wordpress.com/2011/05/02/ nomadic-livelihoods-at-stake-in-rajasthanindia/. [Last accessed on 2019 July 27].

Gibbons ED. (2014). Climate change, children's rights, and the pursuit of intergenerational climate justice. Health Hum Rights, 16(1): 19-31.

Graham S, Barnett J, Fincher R, et al. (2013). The social values at risk from sea-level rise. Environmental Impact Assessment Review, 41(1): 45-52. https://doi.org/10.1016/j.eiar.2013.02.002.

Graham S, Barnett J, Fincher R., et al. (2015). Towards fair local outcomes in adaptation to sea-level rise. Climatic Change 130: 411424. https://doi.org/10.1007/s10584-014-1171-7.

Grothmann T and Patt A. (2005). Adaptive capacity and human cognition: The process of individual adaptation to climate change. Global Environmental Change, 15(3): 199-213.

Inglehart R and Baker WE. (2000). Modernization, cultural change, and the persistence of traditional values. American Sociological Review, 65(1). https://www.jstor.org/stable/2657288.

IPCC TAR. (2001). Climate Change 2001: Impacts, adaptation and vulnerability. IPCC Third Assessment Report, Cambridge: 
Cambridge University Press.

Jones L. and Boyd E. (2011). Exploring social barriers to adaptation: Insights from western Nepal. Global Environmental Change, 21(4): 1262-1274. https://doi.org/10.1016/j.gloenvcha.2011.06.002.

Lokhit Pashu-Palak Sansthan (LPPS). (2004). Saving Rajasthan's camel herds: The perspective of camel breeder. Available from: http:// www.pastoralpeoples.org/saving-rajasthanscamel-herds-the-perspective-of-camel-breeders/. [Last accessed on 2019 April 21].

Roy MM, Louhaichi M, Chand K, et al. (2014). Livestock migration in the arid region of Rajasthan (India): Strategy to cope with fodder and water scarcity. Journal of Arid Land Studies, 24(1): 61-64.

McCubbin S, Smit B, and Pearce T. (2015). Where does climate fit? Vulnerability to climate change in the context of multiple stressors in Funafuti, Tuvalu. Global Environmental Change, 1(30): 43-55. https://doi.org/10.1016/j.gloenvcha.2014.10.007

Nalau J, Handmer J, Dalesa M, et al. (2016). The practice of integrating adaptation and disaster risk reduction in the South-West Pacific. Climate and Development, 8(4): 365-375. https://doi.org/10.1080/17565529.2015.1064809.

Neef A, Benge L, Boruff B, et al. (2018). Climate adaptation strategies in Fiji: The role of social norms and cultural values. World Development, 107:125-137.

O'Brien KL and Wolf J. (2010). A values-based approach to vulnerability and adaptation to climate change. Wiley Interdisciplinary Reviews: Climate Change, 1(2): 232-242. https://doi.org/10.1002/wcc.30.

O'Brien KL. (2009). Do values subjectively define the limits to climate change adaptation. Adapting to Climate Change: Thresholds, Values, Governance, 164-180.

Pareek A and Trivedi PC. (2011). Cultural values and indigenous knowledge of climate change and disaster prediction in Rajasthan. India Indian Journal of Traditional Knowledge, 10(1): 183-189.

Patel SK, Mathew B, Nanda A, et al. (2020). Voices of rural people: Community-level assessment of effects and resilience to natural disasters in Odisha, India. International Journal of Population Studies, 6(1): 3-15. doi:10.18063/ijps.v6i1.1042.

Pelling M, O’Brien K, and Matyas D. (2015). Adaptation and transformation. Climatic Change, 133(1): 113 -127. https://doi. org/10.1007/s10584-014-1303-0.

Piguet E. (2010). Linking climate change, environmental degradation, and migration: A methodological overview. Wiley Interdisciplinary Reviews: Climate Change, 1(4): 517-524.

Land Revenue Portal. (n.d.). Rajasthan Tenancy Act, 1955. Available from: http://www.bareactslive.com/Raj/rj001.htm. [Last accessed on 2019 April 03].

The Energy and Resources Institute. (2010). Draft Rajasthan state action plan on climate change. Available from: http://www.nicra-icar. in/nicrarevised/images/State\%20Action\%20Plan/Rajasthan-SAPCC.pdf. [Last accessed on 2019 July 10].

Ramm TD, Graham S, White CJ, et al. (2017). Advancing values-based approaches to climate change adaptation: A case study from Australia. Environmental Science \& Policy, 76: 113-123.

Rathore MS. (2004). State level analysis of drought policies and impacts in Rajasthan, India. Working paper 93: Drought series paper 6. International Water Management Institute, Colombo.

Rayner S and Malone EL. (2001). Climate change, poverty, and intragenerational equity: The national level. International Journal of Global Environmental Issues, 1(2): 175-202.

Rokeach M. (2008). Understanding Human Values. New York: Simon and Schuster.

Köhler-Rollefson I. (2015). Why Rajasthan's camel protection law is not enough to save its camels. Available from: https://www.downtoearth. org.in/blog/why-rajasthan-s-camelprotection-law-is-not-enough-to-save-its-camels-49292 [Last accessed on 2019 July 20].

Seidel J and Kelle U. (1995). Different functions of coding in the analysis of textual data. In U Kelle (Ed.), Computer-Aided Qualitative Data Analysis: Theory, Methods and Practice (pp. 52-61). London: Sage.

Sharma A, Sharma D, Panda SK, et al. (2018). Investigation of temperature and its indices under climate change scenarios over different regions of Rajasthan state in India. Global and Planetary Change, 161: 82-96.

Sharma P, and Sharma PK. (2015). Tribal entrepreneurship: A socio-anthropological interpretation of nomadic community Raikas. Madhya Pradesh Journal of Social Sciences, 20 (1): 54-69.

Sharma VP, Köhler-Rollefson I, and Morton J. (2003). Pastoralism in India: A Scoping Study. Ahmedabad: Indian Institute of 
Values, environmental vulnerabilities and adaptation in India

Management, Ahmedabad.

Singh RB and Kumar A. (2015). Climate variability and water resource scarcity in drylands of Rajasthan, India. Geo Environmental Disasters, 2(1): 7.

Tripathi H and Rajput DS. (2005). Customs and beliefs of Raika pastoralists of Rajasthan associated with camel husbandry. Indian Journal of Traditional Knowledge, 5(2): 284-286. 